\title{
Immigrant adolescents' adaptation to a new context: Ethnic friendship homophily and its predictors
}

Titzmann, Peter F

\begin{abstract}
Although interethnic friendships are among the best indicators of social adaptation to a new cultural context, adolescent immigrants form friendships predominantly within their own ethnic community, a phenomenon called friendship homophily. In this article, I focus on the acculturation of immigrant adolescents and on the factors that lead them to form friendships within their group, including acculturation-related behaviors, mutual attitudes of native and immigrant groups, developmental agerelated considerations, and the context in which these adolescents live. The results present opportunities not only for reducing friendship homophily but also point to the complexity of acculturation research and the need to study side effects of adolescents' adaptation to a new context.
\end{abstract}

DOI: https://doi.org/10.1111/cdep.12072

Posted at the Zurich Open Repository and Archive, University of Zurich

ZORA URL: https://doi.org/10.5167/uzh-102183

Journal Article

Accepted Version

Originally published at:

Titzmann, Peter F (2014). Immigrant adolescents' adaptation to a new context: Ethnic friendship homophily and its predictors. Child Development Perspectives, 8(2):107-112.

DOI: https://doi.org/10.1111/cdep.12072 


\title{
Immigrant Adolescents' Adaptation to a New Context:
}

\section{Ethnic Friendship Homophily and Its Predictors}

\author{
Peter F. Titzmann \\ Jacobs Center for Productive Youth Development, \\ University of Zurich
}

Ditzmann, P. F. (2014). Immigrant adolescents' adaptation to a new context: Ethnic friendship homophily and its predictors. Child Development Perspectives, 8 (2), 107-112. doi: $10.1111 /$ cdep. 12072

Correspondence concerning this article should be addressed to Peter F. Titzmann, University of Zurich, Jacobs Center for Productive Youth Development, Culmannstrasse 1, Zurich, CH8006, Switzerland; e-mail: titzmann@ jacobscenter.uzh.ch. 


\begin{abstract}
Although interethnic friendships are among the best indicators of social adaptation to a new cultural context, adolescent immigrants form friendships predominantly within their own ethnic community, a phenomenon called friendship homophily. In this article, I focus on the acculturation of immigrant adolescents and on the factors that lead them to form friendships within their own group, including acculturation-related behaviors, mutual attitudes of native and immigrant groups, developmental age-related considerations, and the context, in which these adolescents are embedded. The results present opportunities for reducing friendship homophily, but also point to the complexity of acculturation research and the need to study side effects of adolescents' adaptation to a new context.
\end{abstract}

Key words: friendship homophily, acculturation, adolescent immigrants, interethnic friendships 
Modern multicultural societies have to integrate ethnic and minority groups. In Germany, for example, the share of individuals with a migration background is about $19 \%$ in the general population, $27 \%$ among adolescents, and 33\% among children younger than 10 years (Statistisches Bundesamt, 2010). Successful adaptation is vital for the adolescents themselves and for society. In this review, I focus on immigrant adolescents' friendships as an indicator of their social adaptation to a new context. The number of intra-ethnic friendships is often used to evaluate efforts to reduce segregation (Aboud, Mendelson, \& Purdy, 2003), yet intra-ethnic friendships are still the norm in various ethnic groups (Harris \& Cavanagh, 2008). In Germany, for example, among immigrant adolescents who had recently arrived the former Soviet Union, almost all of their friends were from a similar ethnic background (Silbereisen \& Titzmann, 2007). Although this share decreased over time, it leveled off at about $65 \%$ after seven years (Titzmann \& Silbereisen, 2009). Individual preferences for contact with ethnically similar individuals has been termed ethnic homophily, "the principle that contact between similar people occurs at a higher rate than among dissimilar people” (McPherson, Smith-Lovin, \& Cook, 2001, p. 416). Nevertheless, interindividual variation exists in the share of adolescents' intra-ethnic friends among all their friends. In this review, I refer to this share as as friendship homophily.

To understand interindividual variability in friendship homophily, we must consider the complexity of the sociocultural adaptation of immigrant adolescents. According to a framework on the adaptation of immigrant youth (Motti-Stefandi, Berry, Chryssochoou, Sam, Phinney, 2012), three simultaneous processes play a role: acculturation-related processes referring to adolescents' cultural adaptation to a new context, social-psychological processes based in intergroup relations, and developmental processes of the adolescents' growing up. In addition, adolescents' adaptation is always embedded in a particular environment (Motti- 
Stefanidi, Berry, Chryssochoou, Sam, \& Phinney, 2012) and thus these three core processes are complemented by a fourth aspect--contextual considerations.

In this review, I focus on three core studies that examined predictors of friendship homophily representing the processes and contextual constraints described previously (Titzmann \& Silbereisen, 2009; Titzmann, Silbereisen, \& Mesch, 2012; Titzmann, Silbereisen, \& Schmitt-Rodermund, 2007). These studies compared settings (Israel versus Germany), stages in the acculturation process (newcomers vs. experienced immigrants), and friendship constellations (best friend versus more distant peers). Furthermore, the studies examined the predictors in a multivariate fashion so that we could learn about the net effect of single predictors over and above effects of the other variables.

The research was embedded in a larger project on Diaspora immigrants from the former Soviet Union to Germany and Israel who participated in a longitudinal study covering at least three waves of annual assessment. Both immigrant groups lived in the Diaspora in the former Soviet Union for many generations and are somewhat more privileged compared to other immigrant groups (e.g., they received immediate citizenship and transfer payments; (Shuval, 1998). These immigrants were well-integrated into the Soviet culture (Dietz, 2003) and hardly spoke the new language when they entered their new countries. This may be one reason that the Diaspora immigrant groups from the former Soviet Union face acculturation experiences similar to other immigrant groups (Titzmann \& Stoessel, 2014). Nevertheless, studying these groups in Germany and Israel limits the generalizability of our results to immigrant groups in other parts of the world.

The Acculturation Perspective: Language Use 
Similarity is the backbone of friendships (Hartup \& Stevens, 1997), but immigrants and natives often differ in many ways that can pose barriers for interethnic friendships (e.g., social status or communication; (Maharaj \& Connolly, 1994). The sociocultural adaptation through learning (Masgoret \& Ward, 2006) that is usually observed among immigrant adolescents can be expected to increase similarities between immigrants and natives, and may reduce levels of friendship homophily. One of the strongest indicators in this regard is immigrants' use of the new language (Masgoret \& Ward, 2006). Using the new language not only enhances interethnic communication, but it also conveys an identity, transports knowledge about the new culture (Caldas \& Caron-Caldas, 2002; Gudykunst \& Schmidt, 1987), and may make adolescent immigrants more attractive companions for spare time activities. Using the language of the new country more often should therefore result in more similarity between immigrant and native adolescents, and be associated with less friendship homophily.

Our results support this association. Language use predicted friendship homophily in Israel and Germany, among newly arrived as well as experienced immigrants, and predicted the likelihood of having a nonimmigrant best friend as well as the share of immigrants in the wider friendship network (Titzmann \& Silbereisen, 2009; Titzmann et al., 2012; Titzmann et al., 2007). Furthermore, language use predicted not only the level of friendship homophily, but also interindividual differences in changes over time: That is, as individuals mastered the new language, they had more nonimmigrant friends. Furthermore, immigrants from the former Soviet Union reported higher levels of friendship homophily in Israel as compared to Germany, which was explained by the lower use of the majority language in Israel. Thus, new language is one of the most important tools for interethnic exchange. 


\section{The Intergroup Perspective: Acculturation Orientations and Perceived Discrimination}

In an intergroup perspective, at least two groups need to be considered, immigrants and natives. Immigrants may or may not want contact with members of the receiving society and members of the receiving society may show their negative views of immigrants by discriminating against them.

\section{Acculturation Orientations}

All immigrants—even children and adolescents==vary in terms of their willingness to engage socially (Brown et al., 2013). Acculturation orientations are indicative of such attitudes, which are defined by the two independent questions of whether immigrants want to stay in contact with members of their heritage culture and/or initiate contact with members of the receiving culture (Berry, 1997). According to the theory of planned behavior (Fishbein \& Ajzen, 2010), attitudes were found to predict subsequent behaviors (Armitage \& Conner, 2001). In this regard, a positive orientation toward immigrants' own and/or the other group (attitude) was found to predict the formation of friendships with particular group members (behavior) (Rutland et al., 2012)--probably because the desire for intra- or interethnic peer contact is accompanied by activities that increase the likelihood of meeting native German and/or intra-ethnic adolescents.

In line with these theoretical considerations, we studied acculturation orientations and their association with friendship homophily. Not surprisingly, acculturation orientations strongly predicted friendship homophily. Intra-ethnic orientation was associated with more friendship homophily in Germany as well as in Israel, predicted interindividual differences in longitudinal changes of friendship homophily, and predicted the ethnicity of best friends as well as the ethnic composition of more distant friendships (Titzmann et al., 2012; Titzmann et 
al., 2007). In other words, immigrants who preferred to maintain contact with their heritage culture had more friends from their ethnic group and were less likely to acquire native friends. Furthermore, interethnic and intra-ethnic orientation independently predicted friendship homophily (Titzmann et al., 2007). That is, each of these attitudes predicted friendship homophily even if variations in the other were already accounted for. In short, acculturation orientations seem to be among the strongest predictors of friendship homophily, and increasing willingness for interethnic contact is crucial in creating an atmosphere in which friendships between groups can develop.

\section{Perceived discrimination}

Perceived discrimination is the perception of being treated negatively because of one's ethnicity or membership in a specific cultural group (Jasinskaja-Lahti, Liebkind, Horenczyk, \& Schmitz, 2003). Such perceptions seem valid because perceived discrimination was found to be greater in schools in which natives expressed a more negative view about immigrants than in schools in which less negative attitudes are held (Brenick, Titzmann, Michel, \& Silbereisen, 2012). Such experiences can be expected to increase the level of friendship homophily because exclusion and rejection can heighten identification with one's own ethnic group (Jetten, Branscombe, Schmitt, \& Spears, 2001).

However, in our own studies, we found no convincing evidence linking perceived discrimination and friendship homophily, apart from a single effect in the Israeli group (Titzmann et al., 2007). This effect should not be overemphasized, but the well-developed Russian infrastructure and the greater segregation of the Russian-Jewish community in Israel (Slonim-Nevo, Mirsky, Rubinstein, \& Nauck, 2009) may allow attributions of negative experiences to the "Israeli group" and a withdrawal into the immigrant community. In contrast, in Germany, the immigrant group was always the minority in the new context. Minority members are likely to attribute negative experiences to individual perpetrators 
rather than to "all Germans" (Brewer, Weber, \& Carini, 1995), probably because they also have many positive experiences with other peers. Discriminated adolescents in the minority context may avoid contact with single individuals rather than all Germans per se. Although these explanations are speculative, they suggest the need to examine the effects of group size (minority/majority) in particular contexts and the structure of immigrant communities (Bellmore, Nishina, \& Graham, 2011).

\section{The Developmental Perspective: Adolescents' Age}

The nature of friendships changes across the adolescent years. In early adolescence, friendships provide companionship with common activities, but with age, friendships become more involved, including mutual disclosure and intimacy (Aboud \& Mendelson, 1998). Friends of the same ethnicity are more likely to have a common belief system with similar socio-cultural values, they may face similar (acculturation-related) challenges, and thus they may have a higher mutual understanding that is needed for disclosure (Maharaj \& Connolly, 1994). Thus, friendship homophily was expected to be greater among older as compared to younger adolescent immigrants.

At first sight, our study confirmed these predictions, finding positive associations between age and friendship homophily in immigrant samples in Israel as well as in Germany; but the effects were restricted to cross-sectional analyses (Titzmann et al., 2007). In longitudinal analyses, greater age was related to a more pronounced decrease in friendship homophily in both Israeli (Titzmann et al., 2012) and German samples (Titzmann \& Silbereisen, 2009). These longitudinal associations did not fit our expectations and contrasted with the cross-sectional results. 
One explanation for the contradiction between the cross-sectional and longitudinal age effects relates to natural associations among age, length of residence, and age at immigration (Stevens, 2006). The design of our project ensured that age and length of residence were uncorrelated so that differences between immigrants of different ages could not be attributed to a difference in time spent in the new country. However, this meant that younger adolescent immigrants spent fewer years in the former Soviet Union, probably received their cultural imprint in Germany, and are more similar to their native peers, resulting in less friendship homophily and little change to be expected. Older adolescent immigrants, in comparison, spent more years in the former Soviet Union, may have received their cultural imprint there, and were less similar to native German peers. Thus, their friendship homophily could therefore be expected to be greater initially, but decline as they adapted to the new culture.

In a different study, in which we measured directly the similarity between immigrant and native adolescents (Titzmann \& Silbereisen, 2012)., this scenario was affirmed. We divided our sample into younger adolescents (12.5 years) and older adolescents (16 years). Immigrant adolescents in both groups had been in Germany for about 7 years at the first assessment, so the early adolescent immigrants arrived in Germany at the age of 5.5 years, while the late adolescent immigrants arrived at the age of 9. We assessed adolescents' expectations for oppositional autonomy--their subjective estimation of when it is appropriate to smoke their first cigarette or have their first alcoholic drink--behaviors usually seen in peer contexts.

Such expectations are relevant in forming friendships because they guide adolescents' interests and behaviors (Rosenthal \& Smith, 1997). Less friendship homophily can be expected when autonomy expectations and thus the interests of immigrants and natives are aligned, while greater friendship homophily would occur when natives and immigrants of similar ages differ in their autonomy expectations. 
We found no differences in the initial level or the rate of change in expectations of oppositional autonomy between young adolescent immigrants and younger native adolescents (Titzmann \& Silbereisen, 2012). However, among older adolescents, immigrants reported later autonomy expectations than natives of the same age, but over time, adapted their expectations to those held by native adolescents. This result fits well with our finding of greater initial friendship homophily in older adolescents that declines with increasing age.

These findings demonstrate that age can play various roles in acculturation research. It is not always a pure proxy for normative developmental processes, but can also reflect the degree to which adolescents have been socialized in their heritage culture and their cultural distance to native peers. Researchers need to disentangle age-related changes, acculturation, and the timing of when and how cultural values are formed.

\section{The Context of Adaptation: Contact Opportunities}

Besides the acculturation-related, the intergroup, and the developmental perspective on adolescent immigrants' adaptation, the context of adolescents' adaptation needs to be considered (Motti-Stefanidi et al., 2012). Sociological research (Blau, 1974) and psychological studies (Hallinan \& Teixeira, 1987) assume that opportunities create contact because the basic human need for any contact is stronger than the need for intra-ethnic contact (Blau, 1974). According to these theoretical underpinnings, we can expect contact opportunities (i.e., the share of intra-ethnic individuals in adolescents' close contexts) to be associated with friendship homophily: That is, more opportunities for contact with fellow immigrants should lead immigrant adolescents to have more friendships with other immigrants. 
We studied contact opportunities (i.e., the share of intra-ethnic peers) in various contexts, including the city, the neighborhood, and the school (Titzmann et al., 2007; Titzmann et al., 2011; Titzmann \& Silbereisen, 2009). The share of intra-ethnic peers in school was related to more friendship homophily over and above other factors, which underscores the fact that friendships (a particular form of interindividual contact) are often formed in school (Kiesner, Kerr, \& Stattin, 2004). The effect of the school context was especially apparent in the association of length of residence with friendship homophily (Silbereisen \& Titzmann, 2007): Adolescents in all schools reported that almost all of their friends were intra-ethnic shortly after their arrival in Germany (see Figure 1). But the association between friendship homophily and length of residence depended on the share of intra-ethnic peers in the school context--it was strongest in schools with less than $12 \%$ intraethnic peers, somewhat smaller in schools with $12 \%$ to $30 \%$ intra-ethnic peers, and not significant in schools with more than $30 \%$ intra-ethnic peers. In other words, when immigrant adolescents attended schools where most of their peers were nonimmigrants, over time they befriended these nonimmigrant peers; these friendships did not form in schools where immigrants represented at least $30 \%$ of the student population.

\section{[Insert Figure 1 about here]}

These findings show that interethnic friendships can be brought about in schools. Schools may not only provide the opportunities, they also are likely to meet conditions defined in the contact hypothesis, such as cooperation or support from authorities (Pettigrew, 1998). However, if a critical share of intra-ethnic peers in schools is exceeded (in our study this share was 30\%), interethnic contact apparently is hindered and friendship homophily remains high. Researchers should investigate the mechanisms that link contextual characteristics with the adaptation of immigrant adolescents, as well as whether variations in 
characteristics of the receiving context (e.g., the share of immigrants) can explain differences between immigrant groups in various settings.

\section{Conclusion}

As multicultural societies rely on adolescent immigrants to adapt successfully, we need to learn more about the complexity of immigrants' adaptation to new cultural settings. In this review, I used low levels of friendship homophily as an indicator for sociocultural adaptation to a new society. Acculturation-related, intergroup, and developmental perspectives have to be combined with contextual aspects to reach a deeper understanding of adolescent immigrants' adaptation (Motti-Stefanidi et al., 2012). The specific variables chosen for these four perspectives were based on studies on acculturation and friendship, but other variables could be considered for each perspective and different variables may be decisive for other outcomes. For the study of friendships, the interplay of sociometric measures and ethnicity (Bellmore et al., 2011), the actual quality of friendships (Adams, Bukowski, \& Bagwell, 2005), and the contact conditions (Pettigrew, 1998) would provide additional insights through further research.

This review also provides ideas for reducing friendship homophily by, for example, changing acculturation orientations by creating an open and welcoming receiving context or motivating young immigrants to use language of their receiving country. However, despite the positive effects of interethnic friendships, researchers need to study potential negative side effects because adolescents who adapt to the receiving society can become distant from parents (Hwang, 2006) and family hierarchies can shift (Titzmann, 2012). In addition, this review has focused solely on immigrants, but the role of native adolescents (mainly the majority) in interethnic friendships should not be underestimated as they need to be open to interethnic contact. Nevertheless, identifying factors that relate to friendship homophily 
among immigrants is an important step because in modern multicultural societies, cooperation between groups is essential. 


\section{Author's Note}

I thank Rainer K. Silbereisen and the team at the Center for Applied Developmental Science in Jena for their support of and collaboration in these studies. The research was funded by the German Israeli Project Cooperation (DIP-C 4.1) and the Jacobs Foundation. Correspondence concerning this article should be addressed to Peter F. Titzmann, University of Zurich, Jacobs Center for Productive Youth Development, Culmannstrasse 1, Zurich, CH8006, Switzerland; e-mail: titzmann@jacobscenter.uzh.ch. 


\section{References}

Aboud, F. E., \& Mendelson, M. J. (1998). Determinants of friendship selection and quality: Developmental perspectives. In W. M. Bukowski, A. F. Newcomb \& W. W. Hartup (Eds.), The company they keep: Friendship in childhood and adolescence. (pp. 87112). New York, NY US: Cambridge University Press.

Aboud, F. E., Mendelson, M. J., \& Purdy, K. T. (2003). Cross-race peer relations and friendship quality. International Journal of Behavioral Development, 27(2), 165-173.

Adams, R. E., Bukowski, W. M., \& Bagwell, C. (2005). Stability of aggression during early adolescence as moderated by reciprocated friendship status and friend's aggression. International Journal of Behavioral Development, 29(2), 139-145.

Armitage, C. J., \& Conner, M. (2001). Efficacy of the theory of planned behaviour: A metaanalytic review. British Journal of Social Psychology, 40(4), 471-499.

Bellmore, A., Nishina, A., \& Graham, S. (2011). Peer popularity in the context of ethnicity. In A. H. N. Cillessen, D. Schwartz \& L. Mayeux (Eds.), Popularity in the peer system. (pp. 193-215). New York, NY US: Guilford Press.

Berry, J. W. (1997). Immigration, acculturation, and adaptation. Applied Psychology: An International Review, 46(1), 5-34.

Blau, P. M. (1974). Presidential address: Parameters of social structure. American Sociological Review, 39(5), 615-635.

Brenick, A., Titzmann, P. F., Michel, A., \& Silbereisen, R. K. (2012). Perceptions of discrimination by young diaspora migrants: Individual- and school-level associations among adolescent ethnic German immigrants. European Psychologist, 17(2), 105119. doi: 10.1027/1016-9040/a000118 
Brewer, M. B., Weber, J. G., \& Carini, B. (1995). Person memory in intergroup contexts: Categorization versus individuation. Journal of Personality and Social Psychology, 69(1), 29-40.

Brown, R., Baysu, G., Cameron, L., Nigbur, D., Rutland, A., Watters, C., . . L Landau, A. (2013). Acculturation Attitudes and Social Adjustment in British South Asian Children: A Longitudinal Study. Personality and Social Psychology Bulletin, 39(12), 1656-1667. doi: 10.1177/0146167213500149

Caldas, S. J., \& Caron-Caldas, S. (2002). A sociolinguistic analysis of the language preferences of adolescent bilinguals: Shifting allegiances and developing identities. Applied Linguistics, 23(4), 490-514.

Dietz, B. (2003). Post-Soviet youth in Germany: Group formation, values and attitudes of a new immigrant generation. In T. Horowitz, B. Kotik-Friedgut \& S. Hoffman (Eds.), From pacesetters to dropouts. Post-Soviet youth in comparative perspective (pp. 253271). Lanham, MD: University press of America.

Fishbein, M., \& Ajzen, I. (2010). Predicting and changing behavior: The reasoned action approach. New York, NY US: Psychology Press.

Gudykunst, W. B., \& Schmidt, K. L. (1987). Language and ethnic identity: An overview and prologue. Journal of Language and Social Psychology, 6, 157-170.

Hallinan, M. T., \& Teixeira, R. A. (1987). Opportunities and constraints: Black-White differences in the formation of interracial friendships. Child Development, 58(5), $1358-1371$.

Harris, K. M., \& Cavanagh, S. E. (2008). Indicators of the peer environment in adolescence. In B. V. Brown (Ed.), Key indicators of child and youth well-being: Completing the picture. (pp. 259-278). Mahwah, NJ US: Lawrence Erlbaum Associates Publishers. 
Hartup, W. W., \& Stevens, N. (1997). Friendships and adaptation in the life course. Psychological Bulletin, 121(3), 355-370.

Hwang, W.-C. (2006). Acculturative family distancing: Theory, research, and clinical practice. Psychotherapy: Theory, Research, Practice, Training, 43(4), 397-409. doi: 10.1037/0033-3204.43.4.397

Jasinskaja-Lahti, I., Liebkind, K., Horenczyk, G., \& Schmitz, P. (2003). The interactive nature of acculturation: Perceived discrimination, acculturation attitudes and stress among young ethnic repatriates in Finland, Israel and Germany. International Journal of Intercultural Relations, 27(1), 79-97.

Jetten, J., Branscombe, N. R., Schmitt, M. T., \& Spears, R. (2001). Rebels with a cause: Group identification as a response to perceived discrimination from the mainstream. Personality and Social Psychology Bulletin, 27(9), 1204-1213.

Kiesner, J., Kerr, M., \& Stattin, H. (2004). 'Very Important Persons' in adolescence: Going beyond in-school, single friendships in the study of peer homophily. Journal of Adolescence, 27(5), 545-560. doi: 10.1016/j.adolescence.2004.06.007

Maharaj, S. I., \& Connolly, J. A. (1994). Peer network composition of acculturated and ethnoculturally-affiliated adolescents in a multicultural setting. Journal of Adolescent Research, 9(2), 218-240.

Masgoret, A.-M., \& Ward, C. (2006). Culture learning approach to acculturation. In D. L. Sam \& J. W. Berry (Eds.), The Cambridge handbook of acculturation psychology. (pp. 58-77). New York, NY US: Cambridge University Press.

McPherson, M., Smith-Lovin, L., \& Cook, J. M. (2001). Birds of a feather: Homophily in social networks. Annual Review of Sociology, 27(1), 415-444.

Motti-Stefanidi, F., Berry, J., Chryssochoou, X., Sam, D. L., \& Phinney, J. (2012). Positive immigrant youth adaptation in context: Developmental, acculturation, and social- 
psychological perspectives. In A. S. Masten, K. Liebkind \& D. J. Hernandez (Eds.), Realizing the potential of immigrant youth. (pp. 117-158). New York, NY US:

Cambridge University Press.

Pettigrew, T. F. (1998). Intergroup contact theory. Annual Review of Psychology, 49(1), 6585.

Rosenthal, D. A., \& Smith, A. M. A. (1997). Adolescent sexual timetable. Journal of Youth and Adolescence, 26, 619-636. doi: 10.1023/A:1024538123804

Rutland, A., Cameron, L., Jugert, P., Nigbur, D., Brown, R., Watters, C., . . Le Touze, D. (2012). Group identity and peer relations: A longitudinal study of group identity, perceived peer acceptance, and friendships amongst ethnic minority English children. British Journal of Developmental Psychology, 30(2), 283-302. doi: 10.1111/j.2044835X.2011.02040.x

Shuval, J. T. (1998). Migration to Israel: The mythology of uniqueness. International Migration, 36(1), 3 - 26.

Silbereisen, R. K., \& Titzmann, P. F. (2007). Peers among immigrants - Some comments on 'Have we missed something?'. In R. C. M. E. Engels, M. Kerr \& H. Stattin (Eds.), Friends, lovers and groups: Key relationships in adolescence (pp. 155-166). New York, NY US: John Wiley \& Sons Ltd.

Statistisches Bundesamt. (2010). Bevölkerung und Erwerbstätigkeit. Bevölkerung mit Migrationshintergrund [Population and earning capacity: Population with migrant background]. Wiesbaden: Statistisches Bundesamt.

Stevens, G. (2006). The Age-Length-Onset Problem in Research on Second Language Acquisition Among Immigrants. Language Learning, 56(4), 671-692. doi: 10.1111/j.1467-9922.2006.00392.x 
Titzmann, P. F. (2012). Growing up too soon? Parentification among immigrant and native adolescents in Germany. Journal of Youth and Adolescence, 41(7), 880-893. doi: 10.1007/s10964-011-9711-1

Titzmann, P. F., \& Silbereisen, R. K. (2009). Friendship homophily among ethnic German immigrants: A longitudinal comparison between recent and more experienced immigrant adolescents. Journal of Family Psychology, 23(3), 301-310.

Titzmann, P. F., \& Silbereisen, R. K. (2012). Acculturation or development? Autonomy expectations among ethnic German immigrant adolescents and their native German age-mates. Child Development, 83(5), 1640-1654. doi: 10.1111/j.14678624.2012.01799.x

Titzmann, P. F., Silbereisen, R. K., \& Mesch, G. (2012). Change in Friendship Homophily: A German Israeli comparison of Adolescent Immigrants. Journal of Cross-Cultural Psychology, 43(3), 410-428. doi: 10.1177/0022022111399648

Titzmann, P. F., Silbereisen, R. K., \& Schmitt-Rodermund, E. (2007). Friendship homophily among diaspora migrant adolescents in Germany and Israel. European Psychologist, 12(3), 181-195.

Titzmann, P. F., \& Stoessel, K. (2014). Diaspora Migration in Israel and Germany - Unique Contexts or Examples for a General Phenomenon? In R. K. Silbereisen, P. F. Titzmann \& Y. Shavit (Eds.), The Challenges of Diaspora Migration: Interdisciplinary Perspectives on Israel and Germany (pp. 271-288). Farnham, UK: Ashgate. 
Figure 1: Share of immigrant friends among all friends depending on length of residence in three groups differing in concentration of immigrants at school (taken from Silbereisen \& Titzmann, 2007).

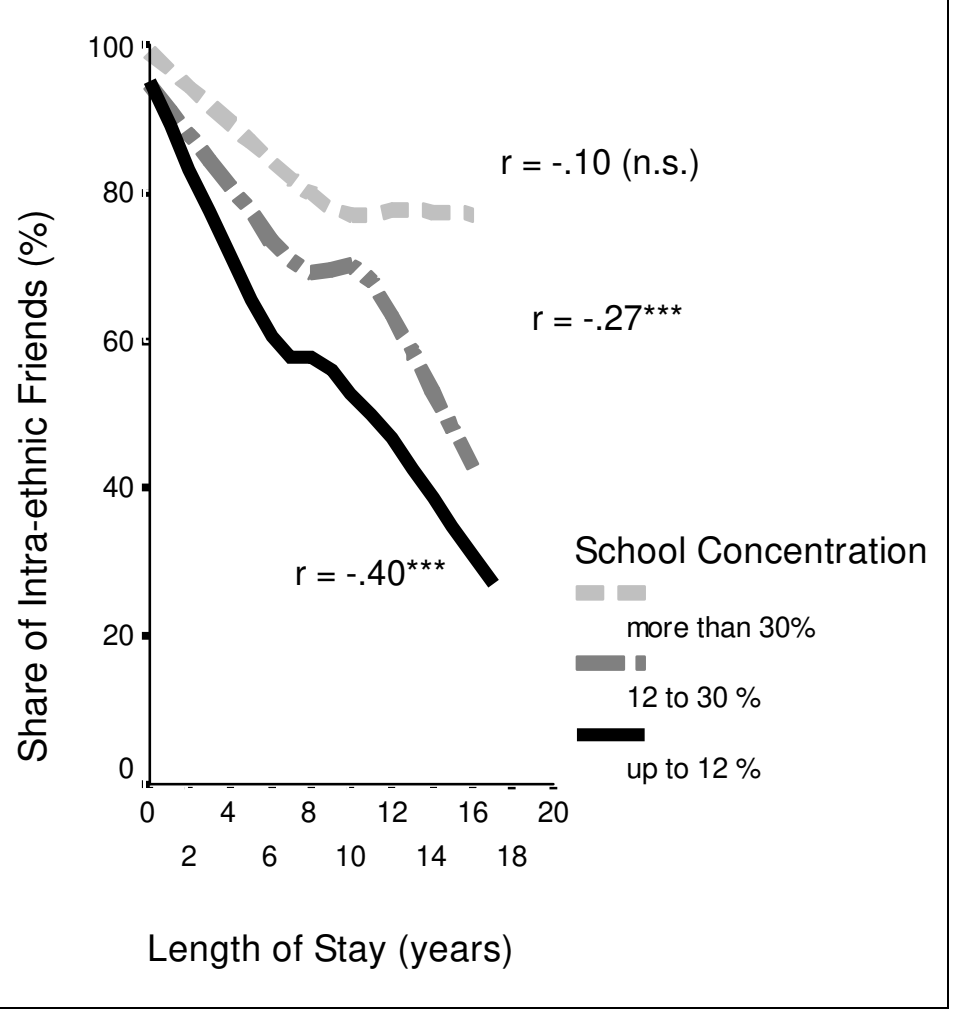

